\title{
Looking back to look forward: a review of human resources for health governance in South Africa from 1994 to 2018
}

\author{
Manya Van Ryneveld ${ }^{1,2^{*}}\left(\mathbb{D}\right.$, Helen Schneider ${ }^{1,2}$ and Uta Lehmann ${ }^{1}$
}

\begin{abstract}
While South Africa has had a fairly consistent record of producing national-level strategic plans for human resources for health in the past 25 years, the country continues to face major problems of affordability, availability, distribution and management of its health workforce. There are several factors contributing to the state of health human resources in the country, but problems with governance stand out as one area requiring further research, analysis and critique. This paper presents a retrospective analysis of the historical patterns in national health human resources governance in South Africa, based on a desktop policy review spanning 25 years after democracy. The authors took a multi-pronged, iterative approach, reviewing policy documents alongside grey and published literature. This led to a timeline showing key legislation, relevant health system and human resource policies, interventions, reviews and evaluations from 1994 to 2018. The review identified three distinct periods that help to characterise the terrain of human resources for health governance over the concerned 25 years. Firstly, a foundational period, in which much of the constitutional and legislative groundwork was laid. Secondly, the HIV epidemic period, which presented a major disruption to the development of system wide governance interventions and improvements. Thirdly, the launch of National Health Insurance discussions and policy processes, which signalled a gradual return to a comprehensive systems focus in line with the founding principles of the first period. Using this periodisation, as well as a conceptual framework of health human resources governance functions based on international literature, the authors argue that South Africa has experienced both progress and challenges in human resources for health governance. This has affected the successful implementation of its policy and strategic planning over the past 25 years. Good governance for human resources for health requires capable stewardship, underpinned by an appropriate mix of technical and administrative skills and explicit political support. The review findings suggest that strengthening human resources for health governance roles, including fostering purposeful stewardship by the National Department of Health, may be key to shifting the terrain in the availability and performance of South Africa's health workforce going forwards.
\end{abstract}

Keywords: Health human resources, Governance, Stewardship

\section{Background}

A global shortage of 15 million health workers is predicted by 2030, with a major concentration of extreme shortages expected in the African region [1]. With

*Correspondence: mvanryneveld@uwc.ac.za

${ }^{1}$ School of Public Health, University of the Western Cape, Robert Sobukwe Road, Bellville Cape Town 7535, South Africa

Full list of author information is available at the end of the article renewed commitments towards universal health coverage (UHC) being made globally, addressing the state of human resources for health $(\mathrm{HRH})$ will be fundamental for any government hoping to honour their commitments. While the importance of HRH development in health systems research is recognised, the practice of governance in relation to the field of $\mathrm{HRH}$ policy and planning is poorly established in many settings [2]. original author(s) and the source, provide a link to the Creative Commons licence, and indicate if changes were made. The images or other third party material in this article are included in the article's Creative Commons licence, unless indicated otherwise in a credit line to the material. If material is not included in the article's Creative Commons licence and your intended use is not permitted by statutory regulation or exceeds the permitted use, you will need to obtain permission directly from the copyright holder. To view a copy of this licence, visit http://creativecommons.org/licenses/by/4.0/. The Creative Commons Public Domain Dedication waiver (http://creativeco mmons.org/publicdomain/zero/1.0/) applies to the data made available in this article, unless otherwise stated in a credit line to the data. 
Structures and capabilities for HRH governance are often under-developed and lacking in political support [3].

It is widely acknowledged that HRH development requires coordination of multiple stakeholders and levels of government [3-5]. Developing comprehensive national HRH policies is just one of the steps towards enabling good governance of, and bridging gaps in, $\mathrm{HRH}$. The capacity required to do so lies principally with national ministries of health, who are well-positioned to play important oversight and stewardship roles. However, a review of HRH units in the ministries of health of 26 countries in the World Health Organization's (WHO) African region reported that most country-level HRH units are "poorly structured, not fit for purpose and lack the ability to influence policy directions" (4, p. 2). Another study showed that, in 2015, only $36 \%$ of countries in the African Region had national-level HRH policy [3].

South Africa (SA) is among those countries with national-level HRH strategic plans, however it continues to face profound health workforce challenges, many of which stem from a lack of effective $\mathrm{HRH}$ governance and high-level stewardship of the implementation of $\mathrm{HRH}$ plans. SA spends $8 \%$ of its GDP on health and $63.4 \%$ of health expenditure in the public sector goes towards health personnel [6]. Despite numerous HRH-related interventions over the last 25 years, the country continues to face major problems of affordability, availability, distribution and management of its health workforce [6]. Health workers are poorly distributed throughout the country, with stark contrasts along rural and urban, and public and private sector lines. Overburdened and poor working conditions, fractious labour relations and punitive organisational cultures exacerbate the problem and are often seen as the frontline push factors that contribute to maldistribution and brain drain.

This paper presents a desktop review and historical analysis of national-level HRH governance and stewardship in SA since the advent of democracy in 1994, through the lens of four key strategic HRH functions and the national-level stewardship capacity required to fulfil these functions. The analysis covers three distinct periods that characterise the historical terrain of the broader health system in South Africa and its impact on HRH governance-the foundational period directly after 1994, a period dominated by the HIV/AIDS epidemic and the more recent shift in focus towards National Health Insurance. A retrospective look at trends and tendencies in HRH governance is an important exercise in consolidating the lessons that can be learnt from the past for policies and plans going forward. This is especially relevant in South Africa, as significant reforms towards National Health Insurance (NHI) and Universal Health Coverage
(UHC) are being advanced, a new 2030 national HRH strategy and 5-year plan is launched, and the impacts of the Covid-19 pandemic are addressed.

\section{Conceptual framework}

To support deeper analysis of the data, a conceptual framework to describe the interaction between the concept of governance and the stewardship function within governance was developed (Fig. 1), based on work done for the WHO Africa Region by Nyoni and Gedik [4] and Afriye et al. [3]. This framework takes the HRH governance function as the overarching concept, understanding it as being steered, in the first instance, through nationallevel HRH processes and structures. The HRH function at national level includes not only well formulated, implementable national-level HRH policy, it should also be enabled to perform its governance function through (i) an appropriate structure and stature of the HRH unit and its programmes within the ministry of health; (ii) strong coordination with regulatory structures and professional councils, (iii) inter- and intra-sectoral coalition building across the levels of government and with relevant departments such as Higher Education and Finance; and (iv) access to and coordination of good-quality health workforce intelligence for decision-making-through routine data collection as well as monitoring and evaluation systems. This requires a strong focus on stakeholder engagement and management across levels and sectors of government, regulatory structures and the professions. In addition, it should be recognised that these components all require political support and leadership and involve a large degree of relational and actor management. Together, these elements make up the stewardship role, which is the (sometimes intangible) cross-cutting component of governance that acts as the "glue" that holds the other planning and implementation functions together.

\section{Methodology \\ Gathering and consolidating resources}

For this review, the authors employed a multi-pronged, iterative methodology, reviewing both literature and a selection of relevant policy documents (see Fig. 2). The first step was to generate a historical overview of HRH policy in SA using the South African Health Review (SAHR) - an annual publication of the Health Systems Trust [7], which documents and comments on the state of SA's health system and has been published annually since 1995. Twenty-seven HRH-related chapters of the SAHR were included. Where the chapters referenced nationallevel HRH policy documents, these were sourced, read and summarised. Scanning of references also led to identification of other relevant literature, supplementary 


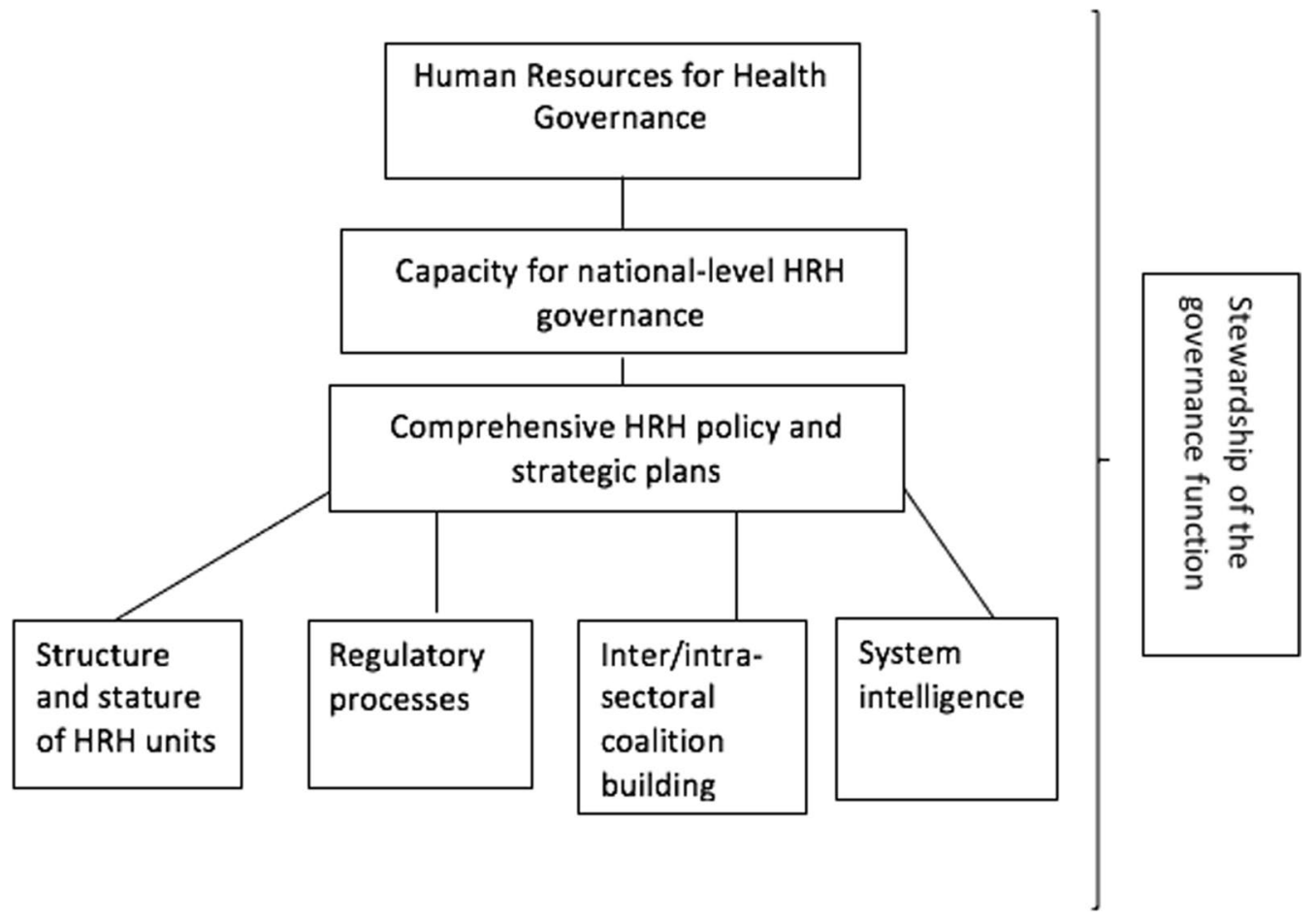

Fig. 1 Conceptual framework of HRH governance, adapted from Nyoni and Gedik [4] and Afriye et al. [3]

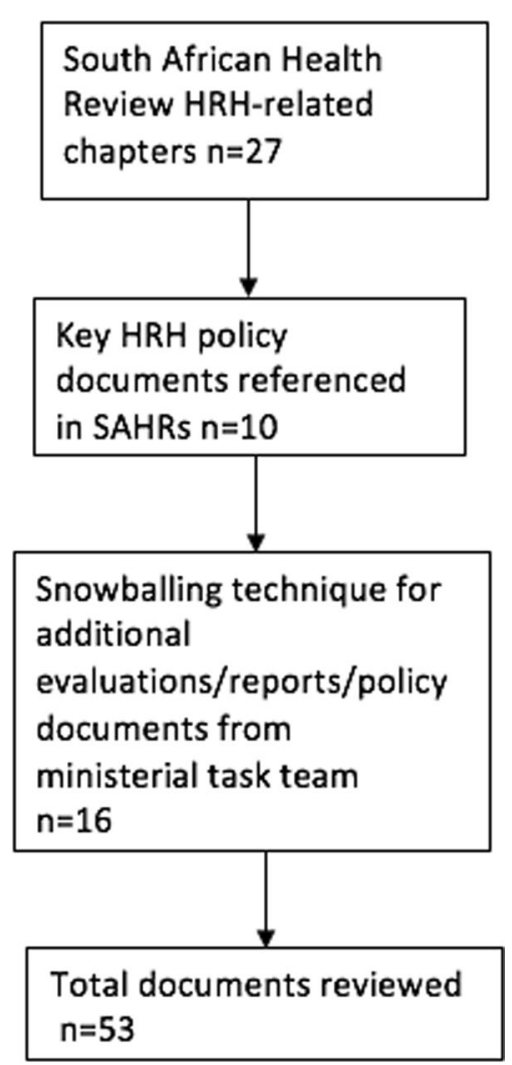

Fig. 2 Flowchart of literature and policy documents reviewed
HRH policy documents, the National Department of Health $(\mathrm{NDoH})$ annual reports, and a number of HRHrelated evaluations conducted at the national level. Relevant historical information was captured on a timeline (see Additional file 1) and an annotated bibliography of national-level HRH interventions and policies was developed. Finally, a version of the review was submitted as an input to a sub-group on Governance and Leadership of the Ministerial Task Team formulating the latest HRH strategy, which identified additional key events for the timeline as well as additional documentary sources to review.

The review findings are structured into six sections. The first two lay out a contextual overview of HRH in South Africa and the historical periodisation of $\mathrm{HRH}$ governance and planning. Then, findings regarding each of the four elements underpinning HRH governance, taken from the conceptual framework, are discussed in the remaining sections.

\section{Unpacking 25 years of HRH governance in South Africa \\ Contextual overview}

While the number of health professionals in SA is higher than most sub-Saharan African countries, SA still faces a crisis of health worker shortages, particularly in the public sector and in rural areas $[8,9]$. This is exacerbated 
by poor distribution and retention due to undesirable work environments, increasingly overburdened staff with shrinking staff establishments, moonlighting and unmanaged remuneration for work done outside of the public sector, an inappropriate skills mix, and the lack of a nationally integrated information system to accurately calculate HRH supply needs, especially at disaggregated levels [9].

SA's health workforce has a mix of established professional cadres, with nurses being by far the largest category. Alongside these professionals are large numbers of community health workers providing outreach, and a relatively small number of mid-level cadres. The introduction of mid-level cadres such as the pharmacy assistant and clinical associate began in the early 2000s, but has faced challenges regarding funding, effective deployment, integration with other health professionals and recognition of their scope of practice by the relevant regulatory bodies [10].

As legislated in the National Health Act of 2003 and the Labour Relations Act of 1995, the various health professions are governed by their respective statutory bodies, who play an important role in regulating the training, registration, community service, continuing professional development and dispensing practices of all health professionals. The function of health professions' education and training is shared across a number of players including university faculties of Health Sciences, Academic Health Complexes, nurse training institutions and the BiMinisterial Join Health Sciences Education Committee (JHSEC).

At the national level, reporting to the Minister and the Director-General of Health, there is a Deputy DirectorGeneral who oversees the budget programme for hospitals, tertiary health services and workforce development. $\mathrm{HRH}$ and responsibilities regarding medium to longterm HR planning, development and management, as well as the office of nursing, belong to this programme. Provincial departments of health are responsible for implementing and funding the national HRH strategy at the provincial level, through advertising and filling vacancies using their provincial HR plans.

\section{Historical overview}

Broadly speaking, HRH governance from 1994 to 2018 can be divided and characterised into three key periods. The first period was a foundational phase immediately post-1994, which saw a major overhaul of policy and legislation and established the frameworks for broader health system transformation, including $\mathrm{HRH}$, in a democratic SA. The focus of this period was one of tackling the racialisation and fragmentation of health care facilities and services, and a shift towards the primary health care (PHC) approach [11]. In 2001 the Department of Health released an unofficial, but wide-ranging and substantially detailed report from the first Ministerial Task Team on HRH - the "Pick Report". Although technically an unofficial document, it laid important groundwork for $\mathrm{HRH}$ thinking in the context of $\mathrm{PHC}$, addressing issues of low production, maldistribution and under-supply of suitable health professionals [12]. The HRH implications of a newly formulated PHC package were outlined in terms of the "staffing gap" and the need for revised scopes of practice and the introduction of mid-level workers. An emphasis was placed on the need for skill audits and surveys as a fundamental component of HRH planning, monitoring and evaluation of progress.

The second period spans the decade between 1999 and 2009, during which SA's health system faced a rapidly unfolding and catastrophic HIV epidemic associated with a massively contested HIV policy terrain. This had a major and multi-faceted impact on the health workforce, firstly, in the rapid increases in workloads, despair and demotivation in the face of death and dying, secondly, in the morbidity and mortality from HIV within the health workforce itself and thirdly, in the under-prioritisation of systems issues (including HRH policy and key health legislation) in lieu of a programmatic focus on HIV [13].

In 2004, the long-awaited National Health Act was finally signed into law, giving the Minister of Health power to create regulations, institutional capacity and governance structures to ensure a well-trained, equitably distributed and retained health workforce for SA. The National Health Act was thus an important legislative step, placing stewardship for $\mathrm{HRH}$ within the remit of the minister and national government. In 2006 the first national HRH strategic plan was released [14]. A national Nursing Strategy was also released in 2008 [15]. The 2006 $\mathrm{HRH}$ strategy was presented as a comprehensive national human resource plan in the context of the recently passed National Health Act, guiding the development of provincial HR plans and serving as a reference point for the private sector and for education and training institutions.

However, the impact of the Act and the strategic plan was limited by a number of factors, including the continued programmatic focus on anti-retroviral (ARV) rollout, various crises in nursing education and training, health worker strikes over the implementation of Occupation Specific Dispensations, and broader austerity measures brought about by the 2008 financial crisis. HRH policy and planning floundered in a health system shaped by vertical, disease-specific programmes and a legislative and policy vacuum regarding the delegation of responsibility for PHC between spheres of government prior to the finalisation of the National Health Act [13]. Many of the important systems-oriented aspirations that were laid 
out in the policy documents of the early democratic years took a backseat in the face of this.

The third phase, from 2009/2010 signalled the start of a gradual return to a comprehensive systems focus in line with the founding principles of the first period, with the release of the Green Paper for National Health Insurance (NHI) in 2009 and the launch of a PHC Re-engineering Strategy in 2011. This coincided with the release of the second national-level HRH strategic plan-the HRH Strategy for the Health Sector 2012/2013-2016/2017 [16] and a Nursing Education and Training strategy [17]. However, the legacy of the previous decade's vertical, disease-oriented response remained embedded in the budget programme structures at national level and the extent of political support for $\mathrm{HRH}$ prioritisation was not explicit, despite the renewed systems focus [18]. With little attention paid to continuity of ideas or pause for evaluation and assessment of what was already in place, $\mathrm{HRH}$ reforms implemented in this period were piecemeal and specific $[16,19]$.

This periodisation exposes a distinct lack of continuity between approaches to HRH planning exercises over the past 25 years. The plans themselves respond predominantly to the varying political and legislative environments of their time (respectively-post-Apartheid transformation, the passing of the National Health Act, and the introduction of $\mathrm{NHI}$ and $\mathrm{PHC}$ re-engineering). Secondly, despite plainly acknowledging many human resource failings, such as poor distribution, brain drain, overburdening and poor working conditions, and being written with actionable goals in the short, medium and long term, implementation of these plans has been undermined by a lack of capacity and failures in other dimensions of the governance and stewardship function-such as the structure and stature of the national $\mathrm{HRH}$ unit, regulatory processes, inter- and intra-sectoral partnerships and coordination, and the access to and use of system intelligence. We examine these dimensions in the remainder of this paper.

\section{Structure and stature of the national HRH unit}

The existence of enabling structures for HRH is central to the overall success of policy implementation. While the framework and structures for HRH governance in SA were established by the National Health Act, performance has been undermined by an under-prioritisation of their functions. The position and stature of the HRH unit within the National Department of Health (NDoH) is a case in point. As the 2003/2004 SAHR pointed out, the Directorate for Human Resource Development has continued to face "high staff turnover rates and a number of vacant posts" undermining the in-house capacity for HRH governance (20, p. 300).
Information on the composition of the national $\mathrm{HRH}$ unit was obtained from the NDoH's annual reports from 2008 onwards, when new organisational structure and budget programmes were introduced (Fig. 3). Between 2008 and 2011, the HRH unit had its own budget programme, with three sub-programmes, entirely dedicated to HR management and development. However, in the 2011/2012 financial year, the department underwent restructuring to improve alignment with national health priorities and manage new nationally controlled conditional grants [18]. HRH no longer had its own budget programme, but instead became a sub-programme of a programme that also included hospital management, health facilities infrastructure and national tertiary services. In 2012/2013, after calls for a Chief Nursing Officer to be established in the department, the office of Nursing Services was introduced and included in this budget programme.

As of the 2017/2018 financial year, human resource development and nursing services remain part of this larger programme, along with hospital and tertiary health services, trauma, violence, emergency and forensic pathology medical services, and health facilities infrastructure planning. This suggests a continued dilution of the HRH unit in favour of programmatic approaches and a budget structure designed on the basis of diseasespecific conditional grants. Without an in-house $\mathrm{HRH}$ unit at national level that functions transversally, is well resourced and politically well-regarded, the capacity to implement even the best strategic plans is undermined.

\section{Regulatory processes}

A key function of $\mathrm{HRH}$ governance is ensuring appropriate regulation of the health workforce. In this regard, SA has relatively well-developed processes, involving a number of health professionals boards representing nurses, medical and dental professionals, pharmacists, rehabilitative professionals, traditional health practitioners and allied health workers. The Health Professions Council of South Africa (HPSCA), the South African Pharmacy Council (SAPC) and the South African Nursing Council (SANC) are the three bodies representing the majority of health professionals in both the public and private sector (Table 1). Community health workers do not as yet have a regulatory board or professional council.

These bodies, many established in the colonial and apartheid eras of a rule bound, hierarchical and militaristic culture in health care [21], are responsible for setting the education and training standards that govern the professions, and regulating their registration, professional conduct, continuing professional development, community service, internship and dispensing practices. This is done in accordance with health-related legislation such 


\section{8-2011 Budget Programmes:}

1. Administration \& corporate services

2. Strategic Health Programmes

3. Health Planning \& Monitoring

4. Human Resources \& Management Development

5. Health Services

6. Health Trade \& Health Production Regulation

\section{1-2012 Budget Programmes:}

1. Administration \& Corporate Services

2. Health planning \& Systems Enablement

3. HIV/AIDS, TB, Maternal, Child \& Women's Health

4. Primary Health Care Services

5. Hospitals, Tertiary Services \& Workforce Development

6. Health Regulation \& Compliance
Programme 4 sub-programmes:

1. HR Policy, Research \& Planning

2. HR Development \& Management

3. Sector Labour Relations \& Planning

Fig. 3 Changes to budget programme structure for HRH at the National Department of Health

Table 1 Statutory bodies regulating health professions in SA

\begin{tabular}{|c|c|}
\hline Health profession & Statutory body \\
\hline Medical doctors and dentists & $\begin{array}{l}\text { Medical and Dental Board of the Health Pro- } \\
\text { fessions Council of South Africa (HPCSA) }\end{array}$ \\
\hline Professional nurses, enrolled nurses and nursing assistants & South African Nursing Council (SANC) \\
\hline Pharmacists and pharmacy support personnel & South African Pharmacy Council (SAPC) \\
\hline Rehabilitation professionals (OTs, physiotherapists, speech therapists) & Professional Boards of the HPCSA \\
\hline Environmental health practitioners & Professional Board of the HPCSA \\
\hline Traditional healers & Interim Traditional Health Practitioners Council \\
\hline Community health workers & None \\
\hline
\end{tabular}

as the National Health Act (2003), the Health Professions Act (1974), and the Nursing Act (2005), and wider legislation such as the Labour Relations Act (1995) and the Skills Development Act (1998).

Despite this relatively strong framework, poor governance within and across the various regulatory bodies, as well as weak coordination with the $\mathrm{HRH}$ unit at $\mathrm{NDoH}$, have resulted in serious regulatory bottlenecks. This has led to a cumbersome, reactive and often punitive regulatory environment, described as impeding health professionals' ability to sit exams, register or practise effectively and impacting on the absorption of much needed foreign
Programme 5 sub-programmes:

1. Hospital Management

2. HR Policy Research \& Planning

3. Health Facilities Infrastructure Management

4. National Tertiary Services Management

5. Sector Labour Relations \& Planning

6. Health HR \& Workforce Management Development 
curtailing their usefulness" (10, p. 835), signalling regulatory capture by the professions.

The alignment between regulatory bodies and national policy, requires strong governance capacity in both $\mathrm{NDoH}$ and the professional boards to ensure that any contestation over new policy can be dealt with timeously and effectively. However, the two major professional bodies, the HPCSA and the SANC have themselves experienced significant governance weaknesses over the past 25 years [23]. In 2015 the HPCSA came under investigation for administrative irregularities, mismanagement and poor governance [22]. Similarly, the 2012/2013 Nursing Education and Training Strategy highlighted "concerns about the SANC's governance, notably its suboptimal leadership and stewardship which has impacted on its professional governance role" (17, p. 24).

\section{Inter/intra-sectoral coalition building}

HRH governance involves working with multiple stakeholders, and requires good coordination, seamless policy dialogue, a shared vision and underlying political will [4]. The 2004 Joint Learning Initiative on Health Human Resources emphasised the need for both strong collaborative approaches and political traction, bringing together stakeholders from the health sector, government and beyond [24]. The responsibility for building and coordinating these relationships lies at the heart of the HRH stewardship function at national level, addressing a complex array of interfaces: between national and sub- national spheres of government; between health and other government departments such as Higher Education, Finance, Public Service and Administration, and Labour; and between government and professional regulatory and higher educational institutions. A lack of strong relationships and channels of bi-directional communication between these different stakeholders has major implications for policy implementation [25].

Health professions' education (HPE) is perhaps the most affected by fragmented relationships across sectors and the lack of a shared vision. A case in point is the crisis in nursing education, which has suffered from a lack of inter-sectoral coordination between the $\mathrm{NDoH}$, Department of Higher Education and Training (DHET) and the SANC [26]. This led to extensive delays in gazetting government regulations for accrediting a new nursing curriculum and the training institutions that will teach it, threatening to curtail the already low production of nurses for the country [27]. Finding a resolution to these reforms over the years has proven difficult, with research citing weaknesses in the leadership and governance capacity of the main nursing institutions to implement appropriate policy [28].
Without strong coordination between the professional councils, NDoH, DHET and Higher Education Institutions (medical schools, nursing colleges, etc.), responding to changing $\mathrm{HRH}$ needs through, for example, developing new curricula, introducing new mid-level cadres or adjusting student intake to encourage rural retention, is difficult. The 2018 Academy of Science of South Africa (ASSAf) Consensus Study reviewed the state of HPE and put forward a number of concrete recommendations for its transformation in light of both NHI and UHC, as well as the stark reality of health professional shortages [29]. Recommendations include revisiting student selection, training and support to improve practice in rural and underserved areas and restructuring curricula for more inter-professional education and collaborative practice, to name a few.

The ASSAf recommendations were underpinned by a call for multi-stakeholder and multi-sectoral approaches, and strong and appropriate governance structures, all of which must be guided by a spirit of collaborative action. To date, a key mechanism for tackling issues of intersectoral collaboration in HPE has been the Bi-Ministerial Joint Health Sciences Education Committee (JHSEC). Established in 2014, it involves both the DHET and the $\mathrm{NDoH}$, with National Treasury as a "participating member", and was set up to "co-ordinate and align strategy, policy and financing in health sciences education" [29]. However, as the ASSAf report points out, the JHSEC has not functioned optimally, while many crises in health professions education remain unresolved. This demonstrates that the mere existence of a collaborative committee is not sufficient to solve complex issues involving inter-sectoral action. A key recommendation in the ASSAf report was the strengthening of JHSEC as a governance structure and "building a joint vision amongst its members" (29, p. 199).

\section{System intelligence}

With respect to $\mathrm{HRH}$, we define system intelligence as the information that contributes to effective $\mathrm{HRH}$ planning-in other words, routine data collection and monitoring and evaluation-as well as the intelligent deployment and usage of this information to improve policy, planning and implementation. As stressed by all of the HRH strategies to date, the HRH information system is not entirely suitable for evidence-based planning and management of $\mathrm{HRH}$. Information comes from disparate sources such as PERSAL- the system used to manage personnel and salaries across the public sector in SA. This database is used as a proxy information system for the public sector health workforce. Given that PERSAL is primarily a pay-roll system designed to manage finances and salaries, it is not well-suited to 
HRH planning and is often poorly updated [30]. Other databases for health workers in the private sector, such as the registries of the professional councils, are also unreliable, often containing health professionals who are no longer working or have left the country [31].

Other avenues for generating information for $\mathrm{HRH}$ planning remain unreliable; the lack of good-quality information is an issue that plagues multiple facets of SA's health system [23]. Evaluations of policy implementation should play an important role in generating valuable HRH planning information. This is particularly so when HRH is in crisis and the purpose of strategic planning is to address chronic underlying difficulties such as poor distribution and low production [32]. In SA there have been no formal evaluations of the implementation of any of the country's official HRH plans to date. While national and provincial governments have processes for internal progress and performance auditing, as well as evaluation systems set up by the Department of Monitoring and Evaluation, external evaluation to generate feedback on the implementation of the plans themselves has not been done. In general, provincial-level HRH plans and evaluation mechanisms are not uniformly understood as sources of system intelligence or workforce planning exercises, but merely as auditing requirements [16]. Where evaluations of $\mathrm{HRH}$-related policy have been undertaken, they have largely been in the context of major health systems crises such as the Integrated Support Teams reports (which documented the crisis of provincial health departments' budgetary shortfalls as a result of failings in both political and administrative leadership), or in response to specific crises such as the maladministration of the HPCSA. Using evaluations only to respond to crises, while important for accountability, undermines their usefulness in generating systematic and continuous feedback information that can contribute towards further improvement of policy and improved performance, management and distribution of the health workforce.

There is also a lack of comprehensive evaluation of the various $\mathrm{HRH}$-related interventions and initiatives. While some, such as community service have been evaluated by independent researchers [33, 34], several major initiatives have never been comprehensively evaluated. A case in point is the Occupation Specific Dispensation, which was a costly intervention aimed at financially incentivising health professionals to remain in the public sector. It was delivered as an unfunded mandate to the provinces, with very little guidance or vision for implementation [16]. The result was a huge financial drain on the provinces, exacerbation of already fractious labour relations and major public sector strikes.

\section{Recommendations}

Based on the key elements of HRH governance outlined in the conceptual framework, it is clear that there are profound weaknesses in (i) the structure and stature of the $\mathrm{HRH}$ unit at $\mathrm{NDoH}$; (ii) alignment of the regulatory bodies with national policy; (iii) the relationships and coalitions between the diverse stakeholders and (iv) the availability of the right kind of information for planning and decision-making. We suggest that strong HRH governance, as well as explicit stewardship of that function, is a key attribute in tackling this and, in the case of SA, requires renewal and clarification of the HRH governance priorities at national level.

Firstly, the HRH unit at NDoH needs to be capacitated to perform its governance function. While good $\mathrm{HRH}$ strategic plans are an important part of this function, they should aim to support the development of further HRH planning at the lower levels of government, rather than lock sub-national departments into fulfilling plans they cannot realistically fulfil. This requires that strong information and monitoring and evaluation systems are in place to facilitate decision-making closer to the frontline. Secondly, there is a need to understand what else can improve the organisational capacity for HRH governance at national level, in particular what Aragón calls the "intangible software"-the values, norms, informal rules and relationships-that are fundamental to effective actor management and establishing a shared vision [35]. This review clearly demonstrates that good governance requires an appropriate mix of skills and explicit political support-it is not purely a technical and administrative function. Thus, it is imperative that all the relevant actors and skillsets are given appropriate legitimacy and authority in the decision-making arena. Finally, HRH governance is an area in dire need of more research and more attention. This requires addressing the "tendency to conflate 'management' with 'governance' which are, in fact, very different terms, albeit closely related" (2, p. 2 ). While HRH management has been fairly comprehensively addressed in the literature, HRH governance remains an elusive knowledge gap. This desktop review has scratched the surface of how poor engagement with national-level governance roles has impacted negatively on $\mathrm{HRH}$ policy implementation and more evidence and analysis is needed.

SA has made some progress in addressing its $\mathrm{HRH}$ challenges and has been able to produce fairly consistent national-level strategic plans that offer some form of strategic vision. Nevertheless, the landscape of $\mathrm{HRH}$ policy and planning is also marked by systemic breakdowns, crisis management, and plugging holes, all of which requires a concerted effort to reverse. Much of this is symptomatic of a lack of continuity between $\mathrm{HRH}$ 
strategic plans, a lack of capacity for stewardship of $\mathrm{HRH}$ policy at national level, and major issues with inter-sectoral and multi-stakeholder collaboration. The findings of this review and analysis using the conceptual framework demonstrate that without strong political support for, and stewardship of, the HRH governance function at the national level, the effectiveness of HRH policy and planning will continue to be undermined. Addressing this will be fundamental to bridging SA's policy-implementation gap, especially with regards to the proposed NHI and UHC policy reforms.

\section{Supplementary information}

Supplementary information accompanies this paper at https://doi. org/10.1186/s12960-020-00536-1.

Additional file 1: Human Resources for Health Timeline. A timeline showing legislative and policy developments in Human Resources for Health in South Africa between 1994 and 2018.

\section{Abbreviations}

ASSAf: Academy of Science South Africa; ANC: African National Congress; ARV: Anti-retroviral; CA: Clinical Associates; DHET: Department of Higher Education and Training; DPSA: Department of Public Service and Administration; HPSCA: Health Professions Council of South Africa; HPE: Health Professions'Education; HRH: Human resources for health; JHSEC: Joint Health Sciences Education Committee; NDoH: National Department of Health; NHI: National Health Insurance; PHC: Primary health care; SA: South Africa; SAHR: South African Health Review; SANC: South African Nursing Council; SAPC: South African Pharmacy Council; UHC: Universal Health Coverage; WHO: World Health Organization.

\section{Acknowledgements}

The authors would like to acknowledge members of the Ministerial Task Team of the Human Resources for Health Strategy 2020 for inputting on the timeline to ensure that it presents a comprehensive overview of $\mathrm{HRH}$ developments in South Africa between 1994 and 2018.

\section{Authors' contributions}

MVR, HS and UL designed the search strategy and the conceptual framework. MVR conducted the search, collated the findings, developed the timeline and drafted the initial manuscript. All authors have revised and approved the final draft of the manuscript.

\section{Funding}

MVR is funded by the South African Medical Research Council's Health Services to Systems Extra-mural Research Unit at the University of the Western Cape.

\section{Availability of data and materials}

Not applicable.

\section{Ethics approval and consent to participate}

This was a desktop review of published and grey literature, therefore no ethical approval or consent process was necessary.

\section{Consent for publication}

Not applicable.

\section{Competing interests}

The authors declare that they have no competing interests.

\section{Author details}

${ }^{1}$ School of Public Health, University of the Western Cape, Robert Sobukwe Road, Bellville Cape Town 7535, South Africa. ${ }^{2}$ Health Services To Systems
Research Unit, South African Medical Research Council, Cape Town, South Africa.

Received: 4 May 2020 Accepted: 16 November 2020

Published online: 26 November 2020

References

1. Rispel L, Blaauw D, Ditlopo P, White J. Human Resources for health and universal health coverage: progress, complexities and contestations. In: Rispel L, Padarath A, editors. South African health review 2018. Durban: Health Systems Trust; 2018. p. 13-21.

2. Dieleman M, Shaw DM, Zwanikken P. Improving the implementation of health workforce policies through governance: a review of case studies. Human Resour Health. 2011. https://doi.org/10.1186/1478-4491-9-10.

3. Afriyie D, Nyoni J, Ahmat A. The state of strategic plans for the health workforce in Africa. BMJ Glob Health. 2019. https://doi.org/10.1136/ bmjgh-2018-001115.

4. Nyoni J, Gedik G. Health workforce governance and leadership capacity in the African Region: review of human resources for health. 2012. http:// www.who.int/hrh/resources/observer9/en/. Accessed 23 Feb 2020.

5. World Health Organization. Global strategy on human resources for health: workforce 2030. 2016. https://www.who.int/hrh/resources/ pub_globstrathrh-2030/en/. Accessed 23 Feb 2020.

6. Blecher M, Daven J, Kollipara A, Maharaja Y, Mansvelder A, Gaarekwe O. Health spending at a time of low economic growth and fiscal constraint. In: Padarath A, Barron P, editors. South African health review 2017. Durban: Health Systems Trust; 2017. p. 25-40.

7. Health Systems Trust. South African health reviews. https://www.hst.org. za/. Accessed 23 Feb 2020.]

8. Sanders D, Lloyd B. Human resources: international context. In: Ijumba P, Barron P, editors. South African health review 2005. Durban: Health Systems Trust; 2005. p. 76-87.

9. Van Rensburg CJ. South Africa's protracted struggle for equal distribution and equitable access - still not there. Human Resour Health. 2014;12(26):1-16. http://www.human-resources-health.com/conte nt/12/1/26. Accessed 23 Feb 2020.

10. Doherty J, Couper I, Fonn S. Will clinical associates be effective in South Africa? S Afr Med J. 2012;102(11):833-5. https://doi.org/10.7196/ SAMJ.5960.

11. Pick W. Human resources development. In: Harrison D, Nielson M, editors. South African Health Review 1995. Durban: Health Systems Trust; 1995.

12. Republic of South Africa National Department of Health \& Human Resources for Health Task Team. Human Resources for Health Strategy (Pick Report). Pretoria. 2001.

13. Lehmann U, Sanders D. Human resource development. In: Ijumba P, Ntuli A, Barron P, editors. South African Health Review 2002. Durban: Health Systems Trust; 2002. p. 119-34.

14. Republic of South Africa National Department of Health. A Strategic Framework for the Human Resources for Health Plan. Pretoria. 2006.

15. Republic of South Africa National Department of Health. Nursing Strategy for South Africa. Pretoria. 2008.

16. Republic of South Africa National Department of Health. Human Resources for Health South Africa: HRH strategy for the health sector 2012/13-2016/17. Pretoria. 2011. https://www.gov.za/documents/human -resources-health-south-africa-hrh-strategy-health-sector-201213-20161 7. Accessed 23 Feb 2020.

17. Republic of South Africa National Department of Health. The National Strategic Plan for Nurse Education, Training and Practice 2012/132016/17. Pretoria. 2013.

18. Republic of South Africa National Department of Health. Annual Report 2011/12. Pretoria. 2012 http://www.health.gov.za/index.php/2014-08-1512-56-31. Accessed 23 Feb 2020.

19. Matsoso MB, Fryatt R. National health insurance: the first 18 months. In: Padarath A, English R, editors. South African health review 2012-2013. Durban: Health Systems Trust; 2013. p. 21-36.

20. Padarath A, Ntuli A, Berthiaume L. Human resources. In: Ijumba P, Day C, Ntuli A, editors. South African health review 2003/4. Durban: Health Systems Trust; 2004. p. 299-316. 
21. Rispel L, Schneider H. Professionalization of South African nursing: who benefits? Int J Health Serv. 1991. https://doi.org/10.2190/ GUHD-GWFQ-YWJJ-EYKH.

22. Mayosi BM, Adam M, Maserumule M, Matlala N, Mgijima R, Mtukushe L. Report of the ministerial task team to investigate allegations of administrative irregularities, mismanagement and poor governance at the Health Professions Council of South Africa (HPCSA): a case of multi-system failure chairperson. 2015. https://www.gov.za/sites/default/files/gcis_docum ent/201511/hpcsa-mttreport.pdf. Accessed 23 Feb 2020.

23. Rispel $L$, Shisana $O$, editors. Confronting the right to ethical and accountable quality health care in South Africa: a consensus report. South African Lancet National Commission. 2018. http://rhap.org.za/wp-content/uploa ds/2019/01/SA-Lancet-Report-Synopsis-South-Africa_Confronting-theRight-to-Ethical-Accountable-Healthcare.pdf. Accessed 23 Feb 2020.

24. Chen L, Evans T, Anand S, Ivey Boufford J, Brown H, Chowdhury M, Wibulpolprasert S, et al. Human resources for health: overcoming the crisis. Lancet. 2004;364(9449):1984-90. https://doi.org/10.1016/S0140 -6736(04)17482-5

25. Van Rensburg D, Van Rensburg N. Distribution of human resources. In Crisp N, Ntuli A, editors. South African Health Review 1999. Durban: Health Systems Trust; 1999. p. 201-32.

26. Mekwa J. Transformation in nursing education. In: Ntuli A, Crisp N, Clarke E, Barron P, editors. South African health review 2000. Durban: Health Systems Trust; 2000. p. 271-86.

27. Armstrong SJ, Rispel LC. Social accountability and nursing education in South Africa. Glob Health Action. 2015;8(May):5-13. https://doi. org/10.3402/gha.v8.27879.

28. Blaauw D, Ditlopo P, Rispel L. Nursing education reform in South Africalessons from a policy analysis study. Glob Health Action. 2014. https://doi. org/10.3402/gha.v7.26401.
29. Academy of Science of South Africa. Reconceptualising Health Professions Education in South Africa. Pretoria. 2018. http://research.assaf.org. za/handle/20.500.11911/95. Accessed 23 Feb 2020.

30. Mathews VE. Decentralised Human Resource Management in a District Health System: case studies in the Western Cape Province, South Africa. PhD Thesis. University of the Western Cape; 2017.

31. Day C, Gray A, Ndlovu N. Health related indicators. In: Rispel L, Padarath A, editors. South African Health Review 2018. Durban: Health Systems Trust; 2018. p. 220.

32. World Health Organization. Policies and practices of countries that are experiencing a crisis in human resources for health: tracking survey. Human Resources for Health Observer. 2010. p. 6. https://www.who.int/ hrh/resources/observer6/en/. Accessed 23 Feb 2020.

33. Reid SJ. Rural health and transformation in South Africa. S Afr Med J. 2006;96(8):676-7. https://doi.org/10.7196/SAMJ.12.13.

34. Reid SJ, Peacocke J, Kornik S, Wolvaardt G. Compulsory community service for doctors in South Africa: a 15-year review. S Afr Med J. 2018:108(9):741-7. https://doi.org/10.7196/SAMJ.2018.v108i9.13070.

35. Aragón O. A case for surfacing theories of change for purposeful organisational capacity development. IDS Bull. 2010;41(3):36-46. https://doi.org /10.1111/j.1759-5436.2010.00135.x.

\section{Publisher's Note}

Springer Nature remains neutral with regard to jurisdictional claims in published maps and institutional affiliations.
Ready to submit your research? Choose BMC and benefit from:

- fast, convenient online submission

- thorough peer review by experienced researchers in your field

- rapid publication on acceptance

- support for research data, including large and complex data types

- gold Open Access which fosters wider collaboration and increased citations

- maximum visibility for your research: over $100 \mathrm{M}$ website views per year

At BMC, research is always in progress.

Learn more biomedcentral.com/submissions 